\title{
La construcción noticiosa de los pueblos indígenas en los principales diarios online de Argentina
}

\section{The news construction of indigenous peoples in the main online newspapers of Argentina}

\author{
Pereyra, R., Alonso, E. y Lencina, R. ${ }^{1}$ \\ Recibido: 29-09-2020 - Aceptado: 25-01-2021 \\ https://doi.org/10.26441/RC20.1-2021-A12
}

RESUMEN: El presente artículo surge a partir de la interrelación de distintas perspectivas teóricas y metodológicas de las áreas de Comunicación y Antropología con la finalidad de analizar el tratamiento mediático de la situación de los pueblos indígenas en el territorio argentino. Para esto se operacionalizan conceptos teóricos de la teoría de Agenda Setting y se desarrolla un análisis de contenido a partir de la recolección de artículos periodísticos de los portales informativos online con mayor alcance en Argentina, en el periodo comprendido entre agosto de 2018 a junio de 2019. Las conclusiones dan cuenta de: una baja cobertura informativa sobre la temática; la construcción y reproducción de sentidos y representaciones en torno a los pueblos originarios vinculado al refuerzo de estereotipos y prejuicios; y escasa oportunidad de los mismos a ser actores y fuentes de la información.

Palabras clave: pueblos indígenas; periodismo; agenda de noticias; Argentina; desigualdad cultural.

\begin{abstract}
This article arises from the interrelation of different theoretical and methodological perspectives in the areas of Communication and Anthropology in order to analyze the media treatment of the situation of indigenous peoples in Argentine territory. To do this, theoretical concepts of the Agenda Setting theory were operationalized and a content analysis was developed from the collection of journalistic articles from the most far-reaching online information portals in Argentina, in the period from August 2018 to June, 2019. The conclusions show: a low information coverage on the subject; the construction and reproduction of meanings and representations around native peoples linked to the reinforcement of stereotypes and prejudices; and little opportunity for them to be actors and sources of information.
\end{abstract}

Keywords: indigenous peoples; journalism; news agenda; Argentina; cultural inequality.

\footnotetext{
${ }^{1}$ Rocío Pereyra es Doctoranda en el programa de Comunicación de la Facultad de Periodismo y Comunicación Social de la Universidad Nacional de La Plata, Becaria doctoral del CONICET e Integrante del Observatorio de Medios, Ciudadanía y Democracia. rociopereyra.cs@gmail.com, https://orcid.org/0000-0002-0791-3115

Exequiel Alonso es Doctorando en el programa de Comunicación de la Facultad de Periodismo y Comunicación Social de la Universidad Nacional de La Plata, Becario doctoral del CONICET e Integrante del Observatorio de Medios, Ciudadanía y Democracia. exealonso@gmail.com, https://orcid.org/0000-0001-7716-8440

Rocío Lencina es Doctoranda en el Área de Antropología en la Facultad de Filosofía y Letras de la Universidad de Buenos Aires, Becaria doctoral del CONICET e Integrante del Programa Interdisciplinario de Estudios sobre el Patrimonio Cultural "PATRIMONIA". rociolencina18@gmail.com, https://orcid.org/0000-0003-0590-2620
} 


\section{Introducción}

El presente artículo surge a partir del trabajo colaborativo entre diferentes disciplinas (Comunicación y Antropología), de la interrelación de perspectivas teórico-metodológicas y de la vinculación de los propios intereses de diferentes investigaciones doctorales.

Realizar un estudio de análisis de contenido en los principales portales informativos online de Argentina implica no sólo indagar los aspectos particulares de la construcción discursiva en torno a una temática, sino también ilustrar y problematizar los modos en los que la información periodística se configura en el entorno digital. Desde la Comunicación consideramos ambos aspectos centrales. Este estudio se inscribe en la producción de dos investigaciones que analizan la construcción de agendas informativas y rutinas productivas.

Desde la Antropología, este trabajo se enmarca en los intereses de una investigación que pretende reconstruir o recuperar el legado cultural indígena desde la perspectiva de las mujeres así como también comprender qué significa ser mujer indígena en la actualidad y en un contexto urbano con una fuerte impronta inmigrante y una gran invisibilización de la presencia originaria.

A partir de un estudio exploratorio, analizamos el tratamiento noticioso y la relevancia otorgada a los pueblos indígenas que habitan el territorio argentino en los portales informativos online Clarín, La Nación, Infobae y Página 12 en el periodo comprendido entre agosto de 2018 y junio de 2019. Proponemos los siguientes objetivos específicos: 1) Identificar la relevancia informativa; 2) Analizar la fisonomía de la temática en los medios a partir de la identificación de tópicos, actores y fuentes predominantes en dicho tratamiento noticioso.

En suma, este trabajo pretende generar un aporte en torno al tratamiento de los pueblos indígenas en la agenda de los portales informativos online más visitados del país con el objeto de indagar: ¿Qué continuidades o discontinuidades con el discurso hegemónico del siglo XIX están presentes en la construcción discursiva de los medios periodísticos analizados? ¿Qué sentidos, representaciones e intereses se ponen en juego cuando se aborda su situación? ¿Qué otros actores aparecen en las notas periodísticas cuando se hace referencia a los pueblos indígenas?

\section{Marco referencial}

\subsection{Contexto histórico del estudio}

Para comprender la complejidad de la realidad actual de los pueblos indígenas que habitan Argentina y cómo impacta la historia en la construcción de sentidos, resulta fundamental contextualizar lo sucedido presentando una breve historización.

Desde fines del siglo XIX, los grupos hegemónicos han intentado invisibilizar, borrar y "normalizar" aquellas marcas que dieran cuenta de las raíces originarias en el territorio negando no sólo su historicidad sino también su presencia (Trouillot, 1995). La "Nación Argentina" se constituyó desde un relato unívoco respecto de su pasado, su historia y su cultura silenciando la multiplicidad y riqueza de legados y orígenes (Balazote y Radovich, 1999). Tal como plantea Mariano (2011) el patrimonio cultural intangible de Argentina es particularmente valioso por su diversidad dado que está integrado por una pluralidad de legados culturales: el de los pueblos indígenas, el colonial, el hispano, el criollo, el afro y el de los inmigrantes de distintas partes del mundo que desde mediados del siglo XIX se asentaron en este territorio.

En este contexto, en el proceso de conformación y consolidación del Estado se construyeron una serie de estereotipos tendientes a profundizar la desigualdad y generar clasificaciones de "sí mis- 
mo" y de los "otros" desde una mirada etnocéntrica, occicéntrica y racista (Alonso, 1994; Curtoni, 2014). Los aportes de Anibal Quijano (2007) sobre la colonialidad del poder permiten comprender la inseparabilidad histórica de la racialización y de la explotación capitalista como constitutivas del sistema capitalista de poder que se ancló en la colonización de las Américas. Así, la incorporación de los pueblos indígenas al Estado supuso el avasallamiento sobre sus tradiciones culturales, la subsunción al sistema de producción capitalista, la subalternización dentro de la estructura de clase, la asimilación como miembros de la ciudadanía con desigualdad de derechos frente al resto y la invisibilidad de estas poblaciones en la vida cívica y en el relato histórico (Crespo, 2011; Lenton, 2014; de la Roca, 2015).

En este marco, no debería llamar la atención que la invisibilidad y la negación del legado cultural originario se reflejara en su gran vacío historiográfico durante el siglo XX (Valverde, 2013; Núñez, 2013; Lazzari et al., 2015). Es recién a partir de la década de 1990 que el imaginario de nacionalidad comienza a flexibilizarse, haciendo lugar a identidades y experiencias antes ocultadas (Lazzari, 2007).

Actualmente, es posible afirmar que tanto en el plano jurídico como en el académico se ha producido una apertura respecto de la mirada que se venía sosteniendo sobre la situación de los pueblos indígenas. Es importante mencionar que esta ampliación de derechos ha sido producto de la lucha de movimientos indígenas no sólo en Argentina sino en toda Latinoamérica. Sin embargo, es necesario explicitar también la brecha en la implementación de las políticas existentes (Stavenhagen, 2007). Esto refleja que si bien son sumamente relevantes las políticas de reconocimiento de los pueblos deben estar acompañadas de políticas de redistribución para "superar" los patrones culturales dominantes y generar una transformación real de su situación. Como indica Nancy Fraser (1997, p. 53): "Esta superación necesita no solo de 'políticas afirmativas' o de mero reconocimiento al modo de las primeras etapas de estos movimientos sociales, sino también de 'políticas transformativas' de las relaciones económicas y simbólicas” (Citado en Bellucci y Rapisardi, 1999).

\subsection{Teoría de Agenda Setting}

La teoría de la Agenda Setting surgió en 1968 con el objetivo de comprobar empíricamente la existencia de una correlación entre las agendas mediáticas y la agenda pública, teniendo como hipótesis central la idea de que los medios en su actuación cotidiana transfieren relevancia de un objeto-tema o figura pública desde su agenda hacia la de los públicos (McCombs y Shaw, 1972).

El estudio fundacional de esta corriente teórica se realizó en la campaña electoral de Estados Unidos en la que compitieron Richard Nixon y Hubert Humphrey. En aquella investigación, McCombs y Shaw realizaron un análisis de contenido sobre la cobertura periodística de la elección y compararon los temas presentes en la prensa con los temas que 100 votantes indecisos reconocieron como importantes. Así, corroboraron que los asuntos destacados en la agenda de los medios se instalan como cuestiones importantes para el público (McCombs y Shaw, 1972). Uno de los conceptos centrales de esta primera etapa de investigación fue el de relevancia, entendida como la asignación de prominencia de los medios hacia determinados temas.

Desde su origen hasta la actualidad la teoría de la Agenda Setting alcanzó nuevas dimensiones de análisis: si la primera etapa pensaba en la transferencia de relevancia de los temas, la segunda propone observar la prominencia de los aspectos o las características particulares asignadas a esos temas (McCombs et al., 1997). En 1997 a este nivel de análisis se lo denominó Agenda de Atributos: "Los medios seleccionan ciertos aspectos de los objetos con los que construyen una representación de la realidad que influye en la percepción de la audiencia" (Zunino, 2018, p. 198). Sobre el segundo nivel de análisis Ghanem lo comparó con las posibilidades de observar un objeto a través de un 
lente de aumento: "Mientras que la agenda de temas no es sino una observación a simple vista los atributos de un objeto son el juego de perspectivas o puntos de vista que los periodistas y el público dedican a su contemplación" (Ghanem, 1997, p. 152).

Para entender cómo los temas y sus atributos llegan a estar presentes en la agenda mediática, McCombs (2006) manifiesta la imposibilidad de los medios de dar cuenta de la totalidad de los acontecimientos que ocurren a diario, dado que existen dos factores determinantes a considerar en toda producción mediática informativa: la capacidad de la agenda del público "ninguna sociedad, con sus instituciones, puede atender a más de un puñado de temas a la vez" (McCombs, 2006, p. 84) y el espacio limitado que posee cada soporte mediático, "incluso en el caso de los sitios web de internet, con su capacidad aparentemente ilimitada de ir añadiendo páginas, nos encontramos con que el alcance y el tiempo disponible de la atención pública imponen severas restricciones" (McCombs, 2006, p. 85). La conjunción de estos dos aspectos genera una gran competencia entre los temas para ingresar en la agenda mediática. Sobre esta competencia cada empresa informativa establece sus criterios de noticiabilidad y relevancia.

\subsection{Movimientos sociales y medios de comunicación: la relación entre el periodismo y los pueblos indígenas.}

La lucha de los colectivos sociales por ser escuchados y visibilizados en la agenda pública es un aspecto central para cualquier sociedad (Peterson y Thörn, 1999): la acción colectiva es un medio para comunicar significados y preexiste al vínculo con el periodismo (Melucci, 1996). Sin embargo, la comunicación mediática "se ha convertido en un factor central para la experiencia política contemporánea" (Manning, 1996 citado en Peterson y Thörn, 1999, p. 14).

La relación entre los movimientos sociales y la industria de los medios de comunicación es compleja y problemática. Los investigadores Smith, McCarthy, McPhail y Augustyn (2001) presentan una exhaustiva revisión bibliográfica que da cuenta de la tensión entre: la posibilidad de los movimientos sociales de ganar estado público a través de la prensa y las características que asumen las coberturas periodísticas (Aruguete, 2015). La hipótesis de los estudios que presentan Smith et al. (2001), es que los movimientos sociales no tienen la posibilidad de influir en el diseño de las políticas públicas, gubernamentales y legislativas, y por lo tanto deben recurrir a la protesta social como un modo de atraer a la prensa, influir en la opinión pública y hacer prevalecer sus intereses. En las conclusiones, Smith et al. (2001) sostienen que las protestas no son el medio más efectivo para comunicar los mensajes del movimiento (Aruguete, 2015), en particular, porque los intereses entre la agenda de estos sectores de la población y la agenda de los medios son diferentes y en ocasiones contradictorias, lo que implica que toda cobertura informativa tiene sesgos que "terminan neutralizando y socavando la propia agenda de los movimientos" (Aruguete, 2015, p. 117).

El investigador Todd Gitlin, en 1965 y desde la perspectiva teórica del encuadre (Framing), analizó la cobertura del periódico The New York Times sobre el movimiento estudiantil norteamericano, en particular, el Student for a Democratic Society (SDS). En las conclusiones de su trabajo, Gitlin (1986) afirma que cuando el SDS logró una alta visibilidad pública, los encuadres del discurso mediático priorizaron la trivialización, la polarización, el disenso interno y el menosprecio por el movimiento (Aruguete, 2015).

En consonancia con estos resultados, Peterson y Thörn (1999) se preguntan si los movimientos sociales son "amigos" o "enemigos" de la industria de los medios, a partir del análisis de diferentes eventos públicos y una detallada revisión de la literatura sobre la temática. En tanto enemigos, los autores mencionan que los periodistas distorsionan la imagen de los movimientos, definen liderazgos a partir del reconocimiento o invisibilización de los actores sociales (Gitlin, 1986) y crean 
nuevos líderes al otorgarles celebridad, con el objetivo de volver dramática y espectacular la acción del colectivo social (Gamson, 1990 citado en Peterson y Thörn, 1999). En tanto amigos de la industria periodística, los movimientos sociales pueden "manipular" a los informantes para llegar a un público más amplio y, por otra parte, abrir nuevos espacios para la "construcción de identidades colectivas, que los movimientos sociales pueden movilizar potencialmente hacia objetivos políticos" (Peterson y Thörn, 1999, p.23).

El investigador Rovira- Sancho (2013) presenta un trabajo sobre la relación entre movimientos sociales mexicanos contemporáneos y la industria de los medios. De acuerdo al autor: "los movimientos sociales no controlan su propia imagen: aunque planean cómo van a manifestarse, dependen de la voluntad y las decisiones de agenda de los grandes medios" (p.37). Peor aún, podrían ser ignorados, criminalizados o tergiversados, dado que los periodistas cuentan con el poder simbólico de legitimar o no la acción de los movimientos sociales (Rovira- Sancho, 2013).

En sintonía con esta preocupación, Rossana Reguillo (2000) se propuso analizar los problemas de los movimientos indígenas para consolidar una imagen de ciudadanía en tiempos de globalización a partir del estudio del caso del Ejército Zapatista de Liberación Nacional (EZLN) en México. La autora presenta las tensiones que vivencian los movimientos populares que buscan en los medios de comunicación un espacio de representación, en particular por lo que implica la aparición de lo "indígena" en el espacio público y mediático luego de décadas de negación por parte de una sociedad que "parece haber apostado por la 'blanquización', lo masculino y lo adulto” (Reguillo, 2000, p. 68).

Para Reguillo (2000) es importante reconocer que hay un proceso de comunicación desigual el cual hace difícil el acceso a los pueblos indígenas al sistema de medios de comunicación, cuyos dueños y aliados son parte de proyectos políticos que tienden a invisibilizar, homogeneizar y/o mercantilizar las diferencias, presentándolas como excentricidad o folklore, que suelen aparecer como notas de color o curiosidades descontextualizadas. Tampoco se trata de reducir la comunicación de los pueblos originarios a medios "alternativos", que resultan insuficientes para disputar los intereses de la agenda pública y llegar a una audiencia masiva.

En esta línea de reflexión, el investigador Damián Andrada compiló el libro "Hacia un periodismo indígena" en el año 2016 para proponer un debate sobre el rol de la comunicación social en la visibilización de las realidades de los pueblos originarios, tanto para transformar desde la comunicación alternativa como para permear las barreras de los medios masivos e industriales. El autor se pregunta: “¿por qué cubrir las luchas indígenas? La respuesta detrás de toda persona que comunica las problemáticas indias es el ánimo de justicia. No es sólo informar. Es dar a conocer algo injusto para que sea transformado" (Andrada, 2016, p. 15).

En ese libro se abordan cuestiones tales como: el impacto de la ley de servicios de comunicación audiovisual en Argentina en los medios de los pueblos originarios y el rol de la Defensoría del Público (Ottaviano y Lamas, 2016); la cobertura de la denominada "conquista al desierto"2 por parte de dos medios de esa época (Fabián, 2016; Forte, 2016); la perspectiva intercultural en Comunicación (Lois, 2016) y la realidad de los medios de pueblos originarios en América Latina (Doyle, Belloti y Siares, 2016; Sirpa Tambo, 2016). Uno de los aspectos centrales de la obra de Andrada, es la propuesta de pensar junto a los líderes y lideresas indígenas el rol de la comunicación, a partir de cuatro entrevistas que recuperan "en primera persona" el vínculo entre los referentes originarios y

\footnotetext{
${ }^{2}$ La noción de "desierto" fue organizada con base en un sistema de clasificación utilizado dentro del discurso dominante para representar a los territorios de Pampa-Patagonia cuando aluden al período previo a la campaña militar de fines del siglo XIX. Así se legitimó la avanzada militar y, una vez anexado el territorio y sometida la población indígena, devino en una estrategia de borramiento, mediante la cual se ordenaron tanto el espacio como los sujetos y las relaciones sociales (Trouillot, 1995).
} 
los medios de comunicación (Ñanku y Wahnish, 2016; Millán y Margarucci, 2016; Díaz y Ferreiros, 2016; Palomo y González, 2016).

Desde el análisis crítico del discurso, Isabella Siqueira Toguchi (2016) presenta su tesis de maestría abocada al estudio de la gramática del prejuicio sobre indígenas brasileños, en los portales de noticias G1, O Globo y Folha de S. Paulo. En sus conclusiones argumenta que estos medios contribuyen al racismo, a partir de metáforas bélicas y encuadres que posicionan a estos pueblos como "preguiçosos, selvagens, violentos, bêbados elou criminosos" (Ibid., p, 157). Desde la misma perspectiva teórica, Sáez Gallardo (2018) analiza el racismo en el diario El Día (Tenerife, España) hacia pueblos originarios y minorías étnicas. El autor evidencia el uso de estrategias lingüístico-discursivas que discriminan a los "otros-étnicos" y presentan una polarización entre un nosotros y un ellos, donde se valora positivamente a la élite blanca y se omite la voz de las minorías. Esta situación de prejuicios, estereotipos y discriminación hacia los pueblos indígenas está presente en las investigaciones de Gertz (2014) sobre la revista alemana Der Spiegel, los aportes de Bandeira de Melo (2004) sobre la prensa en Pernambuco (Brasil) y las investigaciones de Fernandes Braga y Faria Campos (2012) sobre un diario impreso de alcance nacional en Brasil.

Desde otra perspectiva teórica, como es el estudio de la Agenda Setting, diferentes investigadores propusieron analizar la cobertura informativa de los pueblos originarios. Tal es el caso de la tesis de Maestría presentada por Durán Santoyo (2000) titulada: "Presencia, representación y temas indígenas en la prensa mexicana: análisis de contenido de La Jornada, El Norte, Proceso y Época desde la teoría de la Agenda Setting y la Sociología de la producción de mensajes durante el año 2000". En las conclusiones, el autor sostiene que: predominan los asuntos de conflictos y desacuerdos con el gobierno, las fuentes consultadas en su mayoría son población no- indígena, la información es espectacularizada y se presentan a los pueblos originarios como "víctimas, oprimidos, débiles y explotados" (p. 77). En otra tesis de Maestría, la investigadora Saldierna Salas (2011) recupera los principales aportes de la teoría de la Agenda Setting y la teoría del cultivo ${ }^{3}$ para concluir: la presencia de temática indígena en los medios de comunicación no implica un mayor grado de apoyo por parte de la ciudadanía; en proporción este tema aparece con mayor frecuencia en la televisión que en la prensa escrita y el contacto interpersonal con poblaciones indígenas no garantiza mayor empatía a su realidad ni apoyo a políticas públicas destinadas a revertir desigualdades existentes. En la misma línea, Salvador Bezerra (2018) analiza la cobertura informativa de periódicos del Estado de Bahía (Brasil) sobre los derechos de la población Tupinambá y afirma que la "cobertura uniforme descalifica a las legítimas demandas de los nativos. Esta cobertura impide la empatía en favor de aquellos que tienen sus derechos violados" (p. 130). En el artículo titulado: "Análisis de la relevancia informativa en la cobertura del tema Mapuche en la prensa nacional y regional de Chile", los investigadores Hudson, del Valle y Browne (2020) afirman que: la temática mapuche es relevante tanto para la prensa de alcance nacional como regional; los cinco medios analizados encuadran de manera negativa sus noticias, priorizando la criminalización y el énfasis en la violencia; y el pueblo mapuche es invisibilizado como fuente de la información pese a que aparece como el segundo actor de la noticia más veces mencionado. Finalmente, interesa destacar la investigación de Pérez García (2018) porque propone analizar la cobertura informativa que dos periódicos mexicanos, La Jornada y Excélsior, realizaron de María de Jesús Patricio Martínez, la primera candidata indígena a la presidencia de México. En sus conclusiones afirma que uno de los medios se limitó a dar a conocer la propuesta y el otro la estigmatizó a la candidata desde encuadres de ilegalidad y nula chance de obtener una victoria.

\footnotetext{
${ }^{3}$ La teoría del cultivo tuvo su auge en la década de 1960 para estudiar las políticas, programas y efectos de la televisión, a partir del diseño de indicadores culturales. El objetivo de George Gerbner y Larry Gross, sus fundadores, fue comprender las relaciones entre las instituciones, los mensajes y las creencias.
} 


\section{Metodología y conformación del corpus}

Para la investigación se aplicó la técnica de análisis de contenido (AC) a un corpus de 156 artículos periodísticos que fueron publicados entre el $1^{\circ}$ de agosto de 2018 y 30 de junio de 2019 en los portales informativos online Clarín, La Nación, Página 12 e Infobae.

La técnica de AC se caracteriza por permitir la producción de datos a partir de la medición y contrastación de variables aplicadas a un texto. Raymond Colle recuperó aportes de múltiples investigadores que han desarrollado esta técnica (Berelson y Lazarsfeld, 1948; Krippendorf, 1997; Shapiro y Markoff, 1997) y definió a la misma como: "el conjunto de los métodos y técnicas de investigación destinados a facilitar la descripción sistemática de los componentes semánticos y formales de todo tipo de mensaje, y la formulación de inferencias válidas acerca de los datos reunidos" (Colle, 2011, p 7.).

Una propiedad de este tipo de análisis es su sistematicidad, a partir de la implementación de reglas precisas. José Luis Piñuel Raigada (2002) detalló los cuatro pasos que son necesarios explicitar para realizar un análisis de contenido se debe: 1) seleccionar la pieza comunicacional a estudiar, 2) elegir las categorías analíticas que se utilizarán, 3) definir las unidades que serán analizadas y 4) establecer el sistema de medición.

Para nuestro objeto de investigación definimos como pieza a analizar todos los artículos periodísticos publicados en Clarín, La Nación, Infobae, y Página 12 que: 1) incluyeran los términos "pueblos originarios", "comunidades indígenas", "pueblos indígenas", "aborígenes" o "nativos", 2) hicieran referencia a situaciones ancladas en el territorio argentino, 3) se hubieran publicado entre el $1^{\circ}$ de agosto de 2018 y 30 de junio de 2019. Dado que la recuperación de notas publicadas en portales informativos online resulta de gran dificultad para investigaciones de este tipo se procedió a una construcción del corpus de análisis a partir de la búsqueda de palabras clave tanto en archivos de los propios medios analizados como en buscadores de internet. Esto implica destacar que la investigación no pretende generalizar su resultado dado que no es posible garantizar haber obtenido el porcentaje total de notas publicadas por los medios.

De acuerdo al investigador Martín Becerra (2018), el sistema de medios de la República Argentina, en el período que va de la última dictadura militar del año 1976 al año 2019, se caracteriza por:

Primero, la erradicación de la censura directa; segundo, la concentración de la propiedad de las empresas en pocos pero grandes grupos; tercero, la convergencia tecnológica (audiovisual, informática y telecomunicaciones); cuarto, la centralización geográfica de la producción de contenidos, y quinto, la crisis radical del modelo económica en que se sostuvieron las empresas periodísticas durante más de un siglo (p.21)

Como se expresó anteriormente, la selección de los medios contemplados para el análisis se fundamenta con las métricas de consumo semanal que poseen los mismos. De acuerdo a un análisis realizado por Mitchelstein y Boczkowski (2018) para el informe Digital News Report 2018 Clarin, La Nación, Infobae y Página 12 se encuentran entre los 10 portales online de noticias más visitados en Argentina, liderando Infobae y Clarín los primeros dos lugares. Recientemente la consultora privada Comscore presentó los resultados de medición de los portales informativos digitales con mayor cantidad de visitas únicas en Argentina en 2020, estando Infobae, Clarín, La Nación, Página 12 en los primeros cuatro lugares respectivamente.

Los cuatro medios elegidos, además, cumplen las siguientes características: concentran la mayor cantidad de audiencia en todo el territorio nacional; se ubican geográficamente en la Zona Metropolitana de Buenos Aires, por lo que se destaca una fuerte concentración del lugar de la producción de la información; incluyen en su agenda hechos noticiosos que suceden en todo el país (aunque predominan aquellos concentrados en la provincia de Buenos Aires en general y el Área Metropolitana de Buenos Aires) y tienen capacidad de instalar agenda en otros medios que los consideran 
una referencia válida a la hora de producir información. Este fenómeno es denominado dentro de la perspectiva teórica de Agenda como Intermedia Agenda Setting (McCombs, 1992). Es por esta capacidad de instalar temas en la agenda e influir no solo en la opinión pública sino también en otras empresas informativas, que se eligieron los cuatro medios antes mencionados.

Del proceso de búsqueda se logró conformar un corpus de 156 artículos periodísticos, por lo que no se realizó un cálculo de muestreo sino que se trabajó con el total hallado en tanto resulta un universo abarcable. Una vez construido el corpus se procesó el material a partir de la operacionalización en variables de los conceptos de relevancia y atributos.

Para pensar la operacionalización del concepto de relevancia consideramos que "los medios de comunicación le otorgan importancia a los temas a partir de dos factores centrales: la frecuencia de cobertura y la jerarquía de las informaciones" (Zunino, 2016, p. 127). En nuestro análisis observamos la frecuencia temporal en la que se halló información sobre pueblos originarios en la agenda de los medios considerados. Sobre el concepto de jerarquía, si bien no hay criterios estandarizados de aspectos que permiten dar cuenta la asignación de importancia en portales informativos online consideramos como recursos de asignación de prominencia en el tratamiento informativo la presencia o ausencia de fotografías, ilustraciones, videos, redes sociales embebidos, hipervínculos, extensión y firma de autor.

En relación a la noción de agenda de atributos se trabajó desde la dimensión sustantiva del segundo nivel de análisis de la teoría Agenda Setting considerando que "cada asunto o acontecimiento, en su narración como hecho noticioso cuenta con un conjunto de aspectos particulares, aspectos que se definen por el mismo proceso de inclusión y exclusión que funciona en la selección de los asuntos" (McCombs y Evatt, 1995). Para visualizar qué aspectos específicos constituyeron al tema pueblos originarios en la agenda de los medios se codificaron:

- Tópicos: considerando a los mismos como: "acontecimientos noticiosos que, en función de su convergencia semántica, quedan condensados en una categoría más amplia" (Zunino y Aruguete, 2010, p.9).

- Actores: En cada nota periodística se presentan sujetos que constituyen los acontecimientos noticiosos: "un sujeto puede adquirir relevancia en las noticias para ser descrito o, incluso, criticado, pero sin que se le brinde la oportunidad de proveer su interpretación de los acontecimientos en los que participa" (Koziner, 2018, p.103).

- Fuentes: Refieren a aquellos actores o documentos que contribuyen información al tema: "mediante la manifestación de declaraciones -directas o indirectas-, estos aportan información en representación de determinados grupos o instituciones y participan, de algún modo, en la construcción de los hechos relatados" (Koziner, 2018, p.152). Por otra parte, también consideramos fuentes de la información a: "documentos o depósitos de información que pueden ser consultados por el profesional, tales como archivos, libros, revistas, etc" (Marcet y María, 1997, p. 157).

Con estas consideraciones conceptuales y de operacionalización analítica se diseñó un libro de códigos donde se establecieron las siguientes variables: 1) Fecha del artículo, 2) Medio al que corresponde, 3) Género Periodístico, 4) Cantidad de fotografías, 5) Cantidad Ilustraciones, 6) Cantidad de Videos, 7) Presencia de Redes o recursos embebidos, 8) Presencia de Hipervínculos, 9) Extensión de la nota en párrafos, 10) Firma de periodista, 11) Tópico principal, 12) Primeros tres actores mencionados, 13) Primeras tres fuentes citadas.

La variable "tópico principal de la nota" fue construida a partir de una aproximación inductiva sobre 40 notas y quedó constituida con las siguientes categorías: 1) Casos donde se afecta/ó la integridad 
física de las personas; 2) Industria cultural: producciones artísticas culturales que hacen referencia a la situación de los pueblos indígenas; 3) Museos, cultura material y restos humanos de pueblos indígenas; 4) Historias de vida; 5) Encuentros, foros, cumbres o reuniones; 6) Propiedad de la tierra; 7) Educación; 8) Expresiones, prácticas y saberes indígenas; 9) Políticas públicas, decisiones de gobierno y legislación; 10) Violación a los Derechos Humanos; 11) Turismo; 12) Patrimonio en riesgo; 13) Revisión de la historia Argentina; 14) Otros.

Luego de la codificación inicial se incorporó una nueva variable de análisis en relación al espacio asignado a los pueblos indígenas en cada artículo, el cual quedó codificado en 4 categorías: 1) Aparece el término mencionado únicamente; 2) Aparece mencionado con un desarrollo escaso (de uno a dos párrafos); 3) Aparece como tópico secundario de una nota; 4) Aparece como tópico principal de la nota.

Por último, cabe señalar en este apartado metodológico que además de indagar desde la perspectiva anteriormente descripta, que permite contar con la sistematización de evidencia empírica, se utilizó la perspectiva antropológica de manera transversal al proceso de elaboración de las variables y categorías que forman parte del libro de códigos y que, además, permiten el análisis del contenido construido por un actor social en particular que producen discursos y sentidos como lo son los medios de comunicación. Construir conocimiento desde una mirada antropológica implica adoptar una posición de extrañamiento para desentrañar la realidad al punto de poder percibir lo cotidiano como extraño para poder problematizarlo (Lins Ribeiro, 1989). Considerando los planteos de Hammersley y Atkinson (1994), en el caso del relevamiento de medios de comunicación se trataría de realizar una problematización de fuentes documentales de carácter informal. Realizar este proceso analítico desde una mirada antropológica resulta fundamental en tanto estos discursos son constructos sociales que producen y reproducen imágenes, estereotipos y "mitos" socialmente valorados, así como también permiten visibilizar categorías "nativas" que habilitan el relevamiento y la comprensión de la perspectiva del actor (en este caso, los medios de comunicación analizados).

\section{Hallazgos}

\subsection{Descripción general de los resultados del análisis}

Luego de procesar cada una de las notas por la matriz de análisis se puede establecer que la relevancia informativa de los pueblos indígenas en los medios analizados desde el $1^{\circ}$ de agosto de 2018 al 30 de junio de 2019 fue baja: en 334 días de análisis sólo se hallaron 156 artículos en los cuatro medios.

En relación a los aspectos formales que otorgan jerarquía en el tratamiento de la información se indica que de las 156 notas publicadas sobre la temática el 50\% tenían una sola fotografía (muchas de ellas eran fotografías de archivo), el 92,3\% no contenía ilustraciones, el 87,8\% no contaba con hipervínculos, el $84 \%$ no contenía videos, el $92,9 \%$ no presentaba redes o recursos embebidos en el interior del texto, el 52,6\% si contaba con firma de autor y la extensión promedio los artículos fueron de 11 párrafos.

Por otra parte uno de los aspectos más críticos del análisis es arrojado por la variable de espacio asignado a la temática en el artículo, de los 156 artículos solo el 43,6\% consideraba algún tópico vinculado con pueblos indígenas como principal de la nota, el $26,9 \%$ solo mencionaba a las comunidades, en el 18,6\% de los casos aparecía como tópico secundario y en el 10\% restante aparecía mencionada la temática con un desarrollo no mayor a dos párrafos (ver tabla 1). 
Tabla 1. La referencia a los pueblos originarios

\begin{tabular}{|l|c|c|c|c|}
\hline Válidos & Frecuencia & Porcentaje & $\begin{array}{c}\text { Porcentaje } \\
\text { válido }\end{array}$ & $\begin{array}{c}\text { Porcentaje } \\
\text { acumulado }\end{array}$ \\
\hline 1. Aparece el término mencionado únicamente. & 42 & 26,9 & 26,9 & 26,9 \\
2. Aparece mencionado con un desarrollo escaso (un & 17 & 10,9 & 10,9 & 37,8 \\
párrafo). & & & & 56,4 \\
3. Aparece como tópico secundario de una nota. & 29 & 18,6 & 18,6 & 100,0 \\
4. Aparece como tópico principal de la nota. & 68 & 43,6 & 43,6 & \\
Total & 156 & 100,0 & 100,0 & \\
\hline
\end{tabular}

Fuente: elaboración propia en base a resultados obtenidos del procesamiento de datos.

Este dato no parece mostrar un indicador aislado o diferente del resultado de otros estudios como el Monitoreo de Programas Noticiosos de Canales de Aire de CABA realizado por Defensoría del Público de Argentina en 2016 donde la temática en la televisión abierta resultó ser el tópico con menos adjudicaciones de todo el estudio.

Ahora bien: ¿qué subtemas particulares en relación a los pueblos indígenas se hacen presente en la agenda de los medios analizados? En este punto el análisis arrojó una gran disgregación de tópicos, situación que evita presentar a la audiencia continuidades en la información, cada artículo aborda demandas diferentes separadas temporal y geográficamente, tal como presentamos en la tabla 2.

Tabla 2. Pueblos originarios. Tópicos en la agenda mediática argentina

\begin{tabular}{|l|r|r|r|}
\hline Válidos & $\begin{array}{r}\text { Frecuencia } \\
\text { Casos donde se afectan la vida de las personas }\end{array}$ & $\begin{array}{r}\text { Porcentaje } \\
\text { válido }\end{array}$ & $\begin{array}{c}\text { Porcentaje } \\
\text { acumulado }\end{array}$ \\
Violación de los Derechos Humanos & 5 & 9,6 & 9,6 \\
Turismo & 8 & 3,2 & 12,8 \\
Patrimonio en riesgo & 4 & 2,1 & 17,9 \\
Industria Cultural & 27 & 17,3 & 37,8 \\
Museos, Cultura Material, Restos humanos de Pueblos Indígenas & 8 & 5,1 & 42,9 \\
Historias de Vida & 21 & 13,5 & 56,4 \\
Encuenro, foros o reuniones & 13 & 8,3 & 64,7 \\
Propiedad de la Tierra & 9 & 5,8 & 70,5 \\
Educación & 5 & 3,2 & 73,7 \\
Expresiones, Prácticas y Saberes Indígenas & 8 & 5,1 & 78,8 \\
Políticas Púbicas, Actos de Gobierno, Legislación & 12 & 7,7 & 86,5 \\
Historia Argentina y Pueblos Indígenas & 7 & 4,5 & 91,0 \\
Otros & 14 & 9,0 & 100,0 \\
Total & 156 & 100,0 & \\
\hline
\end{tabular}

Fuente: elaboración propia en base a resultados obtenidos del procesamiento de datos.

El tópico con mayor relevancia corresponde a la Industria Cultural (17,3\%) (Ver figura 1 y tabla 2 ), el cual está compuesto por múltiples producciones/manifestaciones artísticas y culturales en las cuales se hace mención a los pueblos indígenas. Este punto resulta interesante para el análisis porque estos actores ingresan a la agenda a partir de que un tercero, generalmente no perteneciente a las comunidades, toma sus demandas y las presenta públicamente en un recital, en un libro, en un documental o ficción. 
La segunda recurrencia de temas fueron Historias de vida $(13,5 \%)$, donde aparecen diversas historias personales no solo de integrantes de pueblos indígenas sino también de personas que no integran las comunidades pero que contribuyen desde acciones solidarias con ellas.

El tercer aspecto con mayor desarrollo con 9,6\% resultó el de los casos en los que se afecta o afectó la integridad física de las personas, aquí se hallan en su totalidad casos fatales donde perdieron la vida integrantes de las comunidades o militantes políticos dentro de los cuales se destacan los casos de Santiago Maldonado, Rafael Nahuel y Agustina Acosta ${ }^{4}$

Figura 1. Pueblos originarios. Tópicos en la agenda mediática argentina.

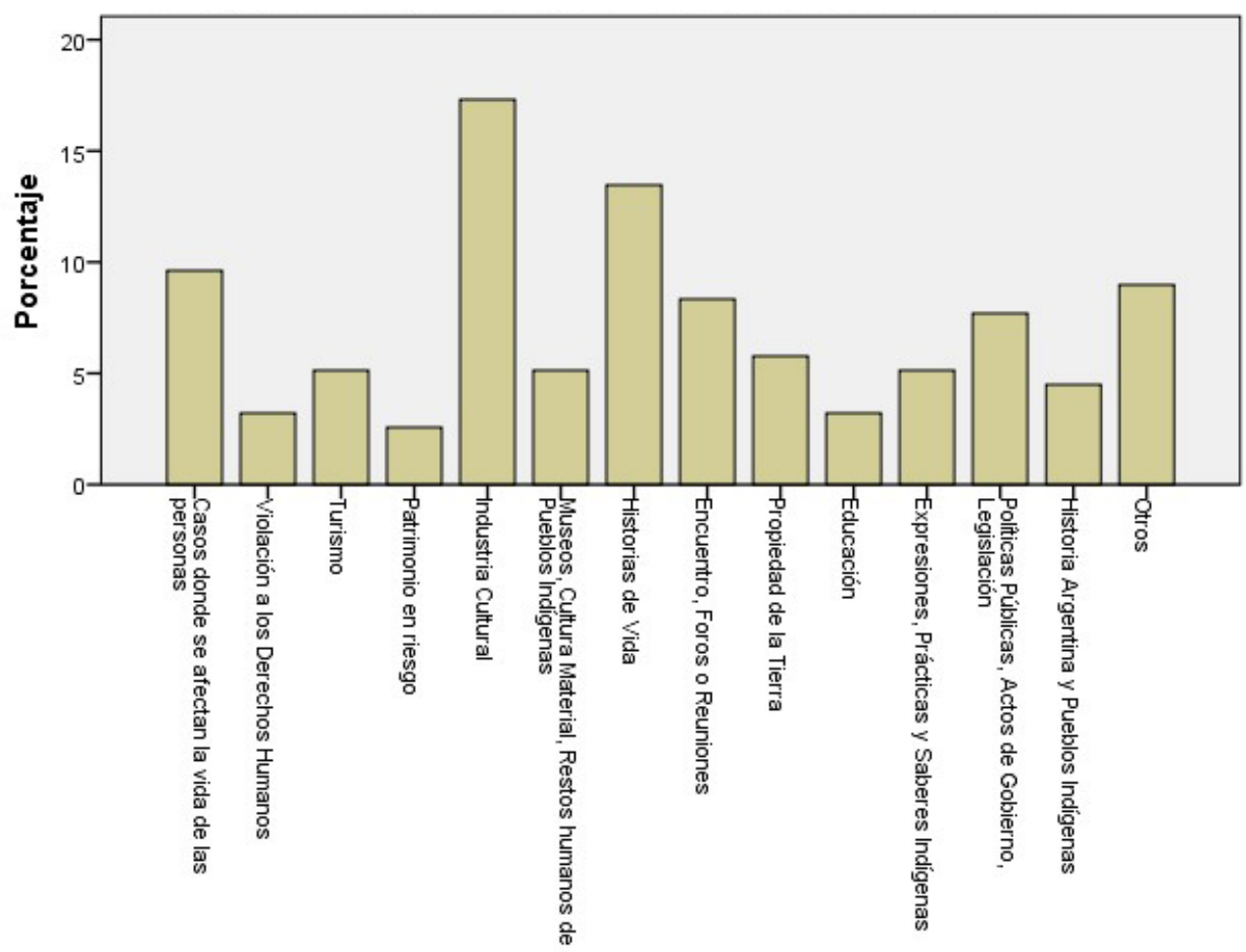

Fuente: elaboración propia en base a resultados obtenidos del procesamiento de datos.

Tanto para la identificación de los actores de la noticias como para las fuentes citadas, se construyeron categorías más amplias que nos permitieron agrupar por lugar de pertenencia a los actores y fuentes mencionadas (ver figura 2).

\footnotetext{
${ }^{4}$ El caso Santiago Maldonado se refiere a la desaparición y asesinato por Gendarmería Nacional del joven de 28 años en 2017 en la Resistencia de Cushamen (Chubut, Argentina). El caso de Rafael Nahuel refiere al asesinato del joven de 22 años perteneciente a la comunidad Mapuche, en una represión de la Prefectura Naval Argentina. El caso de Agustina Acosta hace referencia a la niña de 13 años perteneciente al pueblo wichí que falleció en noviembre de 2018 junto con su bebé prematuro, luego de darlo a luz. Agustina vivenció la desidia del Estado dado que careció de la atención necesaria.
} 
Figura 2. Actores mencionados en las notas.

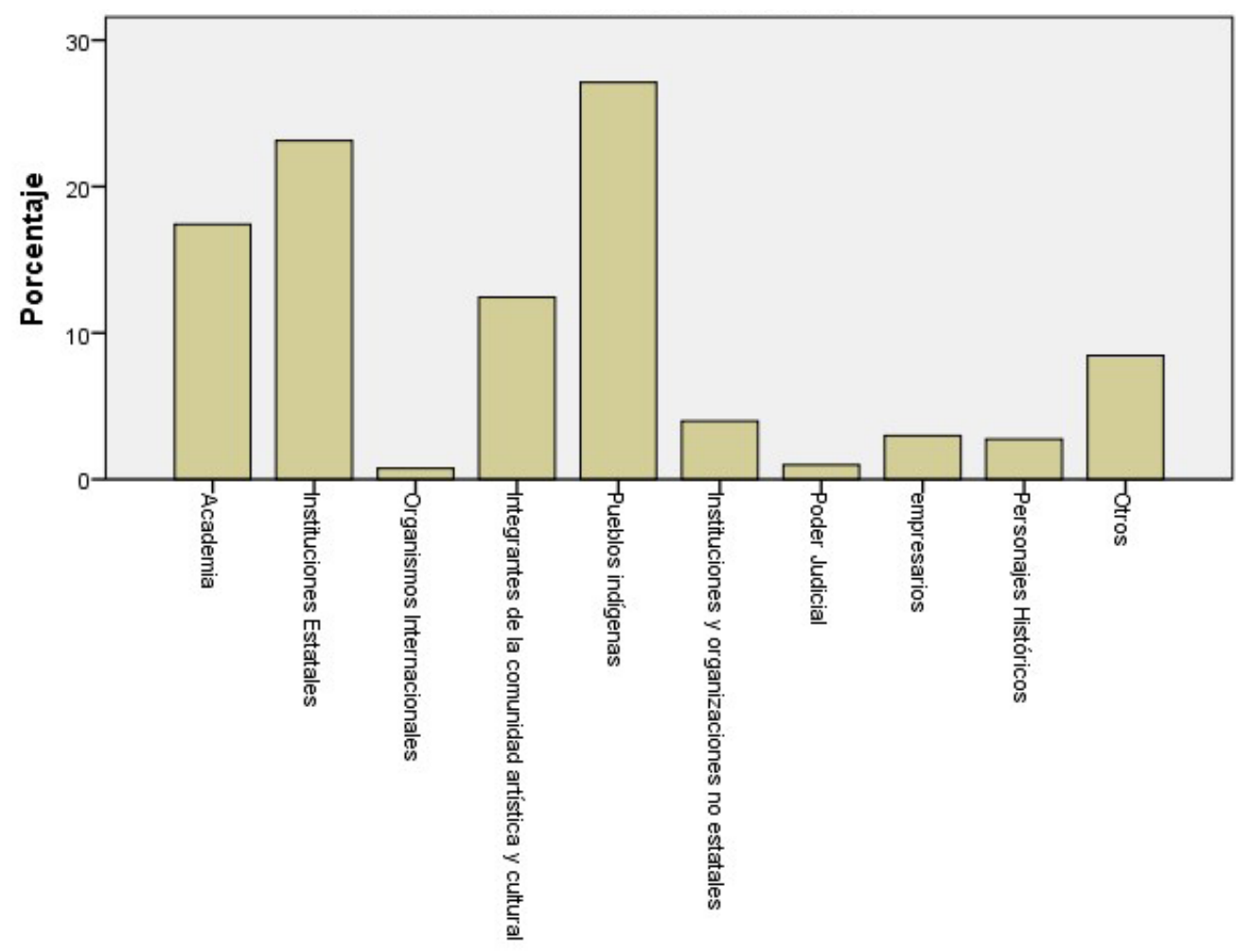

Fuente: elaboración propia en base a resultados obtenidos del procesamiento de datos.

En relación a los protagonistas de los acontecimientos, los pueblos indígenas obtuvieron el mayor porcentaje de presencia $(27,1 \%)$, identificada a partir de la mención de representantes, líderes (18 casos identificados), integrantes (32 casos), comunidades organizadas (48 casos) y alusiones a las comunidades sin definiciones de pertenencia o ubicación geográfica (11 casos). Como segundo actor se ubicó a las Instituciones Gubernamentales y Estatales $(23,1 \%)$, a partir de la mención de reparticiones, ministerios, secretarías, gobernaciones. En este punto es relevante observar el vínculo de estos pueblos con el Estado y cómo las instituciones aparecen en el discurso periodístico como actores sin referencia directa a los representantes políticos a cargo de ellas. En tercer lugar, se encontró a la "academia" (17,4\%), representada por la mención a investigadores (37 casos), instituciones de producción científica (14 casos) y profesionales quienes a través de su ejercicio producen análisis sobre la realidad de los pueblos y naciones originarias (19 casos). El alto porcentaje de mención a la producción académica en los artículos posiciona a la misma como actor legítimo para manifestarse sobre la temática. Del análisis de los principales protagonistas de las notas relevadas se infiere que si bien los pueblos indígenas son el actor mayoritariamente mencionado en relación al total de actores registrados en el corpus su presencia es considerablemente baja (ver tabla 3 ).

Las fuentes de información constituyen un insumo indispensable para la construcción de los acontecimientos en tanto ofrecen modos de lectura de los mismos. De acuerdo con Herbert Gans (citado por Marcet y María, 1997) entendemos por fuentes de información a las personas que el periodista observa o entrevista, que pueden ser o no representantes de grupos organizados de la sociedad y que cumplen la tarea de dar la materia prima necesaria para la construcción de la noticia. En este sentido, nos preguntamos: ¿Quiénes aportaron con su testimonio a la construcción de los acontecimientos en el corpus analizado? 
Tabla 3. Actores mencionados en las notas.

\begin{tabular}{|l|r|r|r|c|}
\hline Válidos & Frecuencia & Porcentaje & $\begin{array}{c}\text { Porcentaje } \\
\text { válido }\end{array}$ & $\begin{array}{c}\text { Porcntaje } \\
\text { acumulado }\end{array}$ \\
\hline Academia & 70 & 17,4 & 17,4 & 17,4 \\
Instituciones Estatales & 93 & 23,1 & 23,1 & 40,5 \\
Organismos Internacionales & 3 &, 7 &, 7 & 41,3 \\
Integrantes de la comunidad artística y cultural & 50 & 12,4 & 12,4 & 53,7 \\
Pueblos indígenas & 109 & 27,1 & 27,1 & 80,8 \\
Instituciones y organizaciones no estatales & 16 & 4,0 & 4,0 & 84,8 \\
Poder Judicial & 4 & 1,0 & 1,0 & 85,9 \\
Empresarios & 12 & 3,0 & 3,0 & 88,8 \\
Personajes Histórícos & 11 & 2,7 & 2,7 & 91,5 \\
Otros & 34 & 8,5 & 8,5 & 100,0 \\
Total & 402 & 100,0 & 100,0 & \\
\hline
\end{tabular}

Fuente: elaboración propia en base a resultados obtenidos del procesamiento de datos.

En aquellos casos donde fue posible computar las fuentes de la información, las más consultadas fueron las "académicas" (21\%), es decir aquellas que fundamentan su inclusión desde el conocimiento científico o experto sobre una temática particular. En segundo término, se encontraron las voces de los pueblos indígenas $(17,3 \%)$ quienes generalmente manifiestan sus problemáticas, demandas, preocupaciones, saberes, tradiciones culturales. En tercer lugar, se hallaron las fuentes institucionales del Estado (13,2\%), representadas en el discurso de funcionarios y legisladores. Finalmente, los artistas y representantes del ámbito cultural (12,2\%) que al expresar solidaridad a las luchas del movimiento indígena en Argentina poseen un lugar recurrente en la agenda mediática (ver tabla 4 y figura 3 ).

Tabla 4. Fuentes citadas.

\begin{tabular}{|l|r|r|c|}
\hline Válidos & Frecuencia & $\begin{array}{c}\text { Porcentaje } \\
\text { válido }\end{array}$ & $\begin{array}{c}\text { Porcntaje } \\
\text { acumulado }\end{array}$ \\
\hline Academia & 62 & 21 & 21,0 \\
Onstituciones Estatales & 9 & 3,1 & 24,1 \\
Integrantes de la comunidad artística y cultural & 2 &, 7 & 24,7 \\
Pueblos indígenas & 51 & 12,2 & 36,0 \\
Instituciones y organizaciones no estatales & 20 & 17,3 & 54,2 \\
Poder Judicial & 20 & 6,8 & 61,0 \\
Empresarios & 1 & 6,8 & 67,8 \\
Funcionarios Políticos, Legisladores & 39 & 13,2 & 68,1 \\
Leyes y Normativas & 9 & 3,1 & 84,4 \\
Familiares de víctimas & 8 & 2,7 & 100,0 \\
Otros & 38 & 2,9 & 97,3 \\
Total & 295 & 100,0 & \\
\hline
\end{tabular}

Fuente: elaboración propia en base a resultados obtenidos del procesamiento de datos. 
Figura 3. Fuentes citadas.

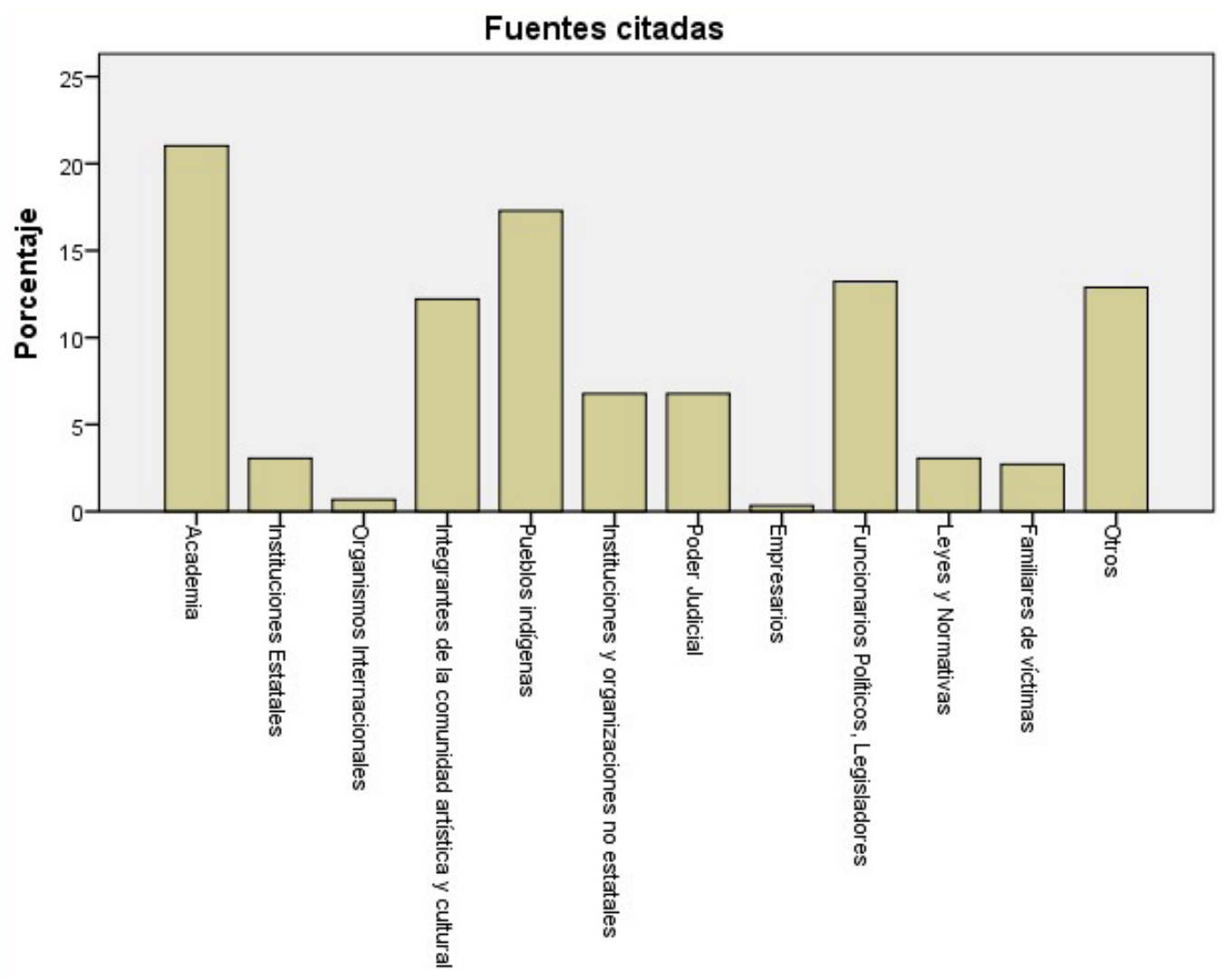

Fuente: elaboración propia en base a resultados obtenidos del procesamiento de datos.

La manera en que los medios tratan un determinado tema y los atributos que le asignan es clave para considerar su relevancia en la agenda pública. Hasta aquí, los resultados obtenidos dan cuenta de una baja cobertura de las problemáticas de los pueblos indígenas, diversificación de tópicos, baja consideración como actores y como fuentes de la información. Este dato es aún más alarmante si tenemos en cuenta que el corpus seleccionado incluye aquellas noticias que, al menos una vez, menciona a los pueblos originarios.

\subsection{Discusiones: imágenes, sentidos y representaciones sobre "lo indígena"}

Del análisis de los resultados identificados, consideramos importante analizar los sentidos que esta cobertura deja implícitos. En particular nos interesa recuperar cuáles son las imágenes construidas en relación a los pueblos indígenas en los portales informativos online, sosteniendo como hipótesis que se trata de representaciones estereotipadas y deshistorizantes sobre estos actores. Tal como afirman las primeras investigaciones sobre movimientos sociales (Smith, 2001; Gitlin, 1986) la dificultad de las minorías étnicas para visibilizar sus temas y ganar espacio en la agenda, es una persistencia en los medios analizados. Sin embargo, a diferencia de estos primeros antecedentes que estudiaban como las protestas eran la llave para acceder a los medios masivos de comunicación, en el caso de Argentina, los actos de reclamos de los pueblos originarios no trascienden en los grandes medios de la Capital Federal y son cubiertos por prensa especializada o regional. En nuestra investigación hallamos que el hueco de cobertura informativa de la temática indígena considerando la producción de los cuatro portales online más visitados de la Argentina en 365 días de análisis no llega a una noticia por día (0,46 \% notas). A esta escasa presencia se le suma una baja jerarquía en el tratamiento, por lo que nos encontramos con una visibilidad reducida que confirma la idea de que 
los pueblos indígenas no controlan su imagen pública (Rovira-Sancho, 2013) y su agenda es socavada por los intereses editoriales y comerciales de los medios de comunicación (Aruguete, 2015).

El papel de los medios resulta clave en la presentación sesgada por patrones culturales dominantes y repetitivos en torno a determinados grupos sociales (en general minoritarios) en sus contenidos informativos o de ficción, construyendo ciertas imágenes que contribuyen en la configuración de estereotipos raciales y/o étnicos (Dixon, 2000). A su vez, vale mencionar su influencia en la percepción de las personas particularmente cuando estas imágenes se repiten de forma constante y sostenida en el tiempo convirtiendo ese imaginario en una fuente de información tomada por las personas como conocimiento "válido" y "objetivo" (Brown-Givens y Monahan, 2005). En palabras de la comunicadora indígena Eliana Champutiz: "Estos imaginarios, que los medios de comunicación nos van vendiendo (...) van creando un estereotipo de persona, de cultura, de comportamiento y se convierten en el paradigma al cual debemos aspirar" (CHIRAPAQ5 , 2013, p. 21).

En relación a esto último, se puede visibilizar cómo se presentan tensiones entre lo que desde una mirada "idealizada" se concibe como "lo indígena" y lo que acontece en la realidad social. En los resultados presentados, sólo el $43 \%$ de las noticias tuvieron como asunto principal de la historia a los pueblos originarios y sus problemáticas, es decir cuando se habla de lo indígena en los medios analizados, en más de la mitad de los casos aparece como un tópico secundario $(18,6 \%)$ o directamente como una mención generalista y sin profundizar, similar situación a la que describe Reguillo (2000) respecto al tratamiento del EZLN como "folklore" o "excentricidad". Esta cobertura descontextualizada y fragmentada puede pensarse en relación a los catorce tópicos codificados en las noticias recabadas. Esta diversidad atenta contra una agenda unificada de demandas y reclamos y construye una mirada hegemónica y colonial sobre los pueblos originarios, tal como advierten los aportes de Siqueira Toguchi (2016) y Bandeira de Melo (2004) en la prensa de Brasil; Sáez Gallardo (2018) en España; y Gertz (2014) en Alemania.

Asimismo puede advertirse la construcción de estereotipos vinculados a lo que es ser indígena, mostrándolos desde una mirada "esencialista", armoniosa y equilibrada. Este relato no sólo invisibiliza sino que contribuye a negar uno de los genocidios ${ }^{6}$ más grandes de la historia: parecería ser que se "oculta" detrás de esta mirada esencialista la profunda situación de vulnerabilidad y desigualdad en que se encuentran los pueblos originarios, motivo por el cual estos pueblos se organizan y luchan para que se garanticen los derechos que en la legislación se les reconocen a la vez que se atiendan a sus demandas. No obstante, se ha señalado que debiera evitarse que este tratamiento lleve a visibilizarlos sólo desde sus carencias. Por el contrario, un enfoque de derechos debiera permitir trascender la actitud asistencialista por una de reconocimiento de sus particularidades y demandas como legítimas, la redistribución de los recursos y la apertura de espacios para su desarrollo (Aparicio Wilhelmi, 2006).

Por otro lado, se observa cómo las imágenes construidas como producto de los procesos ideológicos conducidos por las élites dominantes en el siglo XIX siguen siendo reproducidas por la mayoría de los portales informativos considerados para este análisis. Esto se manifiesta en la escasa representatividad de las voces, testimonios y agendas políticas de los pueblos indígenas como principales fuentes de información así como en la preponderancia de fuentes "académicas" y "expertas" para

\footnotetext{
${ }^{5}$ En referencia a la asociación indígena: Centro de Culturas Indígenas del Perú (CHIRAPAQ). Para más información: http://chirapaq.org.pe/es/.

${ }^{6}$ Se entiende al genocidio como "una práctica y un proceso, el cual se inicia antes y concluye mucho después de los actos que el Estado argentino perpetró contra los pueblos originarios con el objetivo de desestructurarlos: matanzas, traslados, confinamientos en campos de concentración, apropiación y distribución de niños y adultos para distintas funciones, el acoso a territorios y asalto a recursos que afectan su supervivencia" (Mariano Nagy, 2018, p. 66).
} 
dar cuenta de su situación y sus demandas. Los pueblos originarios tienen escasas posibilidades de hacer escuchar su voz, en representación de ellos mismos, en los portales analizados. En primer lugar, porque ingresan a la agenda mediática por tópicos relacionados a producciones de la industria cultural (quienes hablan son cineastas, documentalistas, artistas, pintores, músicos que no siempre son indígenas). En segundo lugar, porque cuando se dan lugar a las historias de vida se pone el eje en una perspectiva individual y descontextualizada, apartando al individuo del colectivo al cual pertenece.

Al igual que en los hallazgos de Hudson, del Valle y Browne (2020), los pueblos originarios aparecen como actores de las noticias en el mayor porcentaje de las mismas pero no como fuentes de información, ocupando solo un $17,3 \%$ del total de noticias donde fue posible computar esta categoría. En este punto encontramos una similitud con el trabajo de Durán Santoyo (2000) presentado anteriormente. A diferencia de las fuentes de pueblos indígenas, si contamos a la academia $(21 \%)$, instituciones estatales $(3,1 \%)$ y funcionarios y legisladores del Estado $(13,2 \%)$, observamos que la temática indígena no solo está fuertemente vinculada a los actores del Estado, sino que además los mismos son el principal insumo de información (37,3\%).

Siguiendo los planteos de Escolar, Del Río y Malvestiti (2010) la construcción mediática de los pueblos indígenas que habitan el territorio argentino tiende no sólo a invisibilizarlos sino también a criminalizar sus demandas restándole legitimidad a sus reclamos, vulnerando sus derechos y contribuyendo a profundizar la brecha de implementación de la legislación vigente:

Estas mismas imágenes son reflotadas hoy por cronistas con llegada a un público masivo que argumentan la "cientificidad" de sus dudosas y ampliamente refutadas interpretaciones a fin de esgrimir un discurso que impugna todas las demandas indígenas, sus derechos a la tierra, su existencia como pueblos y su propia existencia como "verdaderos" indígenas. (Escolar, De Río y Malvestiti, 2010, p. 294)

Esta criminalización de los reclamos, que ocupan un lugar marginal en la agenda de los medios analizados, se complementa con coberturas sensacionalistas y, en algunos casos, circulación de información errónea que no hace más que deslegitimar las acciones colectivas y desfavorecer la empatía y solidaridad del resto de la población. Los trabajos de Hudson, del Valle y Browne (2020) en la cobertura del pueblo mapuche; Salvador Bezerra (2018) respecto a la comunidad Tupinambá o Saldierna Salas (2011) con los indígenas en México, dan cuenta de resultados similares.

\section{Conclusiones}

La investigación efectuada se propuso analizar la relevancia mediática de los pueblos indígenas en los principales portales digitales informativos de Argentina a partir de 1) identificar la relevancia informativa y 2) analizar la fisonomía de la temática a partir de la identificación de tópicos, actores y fuentes predominantes en dicho tratamiento noticioso. Los resultados obtenidos nos permiten plantear las continuidades del discurso hegemónico del siglo XIX en la construcción discursiva de los artículos considerados. Los medios han jugado (y juegan) un rol central en la invisibilización del genocidio sobre los pueblos originarios y en la construcción de un no-relato del mismo. Recuperando a Bidaseca (2011, p. 27), podríamos hablar de un colonialismo discursivo cuando las voces de estos grupos "no aparecen, son fagocitadas o representadas y cuando lo hacen deben pedir permiso". Aún en el presente gran parte de la sociedad argentina se percibe a sí misma como resultado de un "crisol de razas europeas" resultantes de un proceso histórico incruento de colonización de un territorio que se presume "desierto" hasta el momento de la expansión del moderno Estado-Nación a fines del siglo XIX (Lenton et al., 2015). De este modo, se observa una tendencia a caracterizar a los pueblos indígenas como "cosas del pasado" y cuando se reconoce su existencia en el presente se los suele "etiquetar" como grupos "vulnerables" y "desempoderados" desde una mirada asistencialista, describiendo la necesidad de alcanzar mejores condiciones de vida pero sin profundizar 
sobre las causas estructurales de esta desigualdad. No obstante, cuando en las notas periodísticas se recuperan acciones de protesta de los pueblos indígenas en lugar de explicitar las demandas allí presentes se limitan a concebirlos como sujetos "amenazantes", "salvajes" o "peligrosos" desde una mirada estigmatizante, recuperando (a veces de manera explícita) la imagen del "malón indio" tan característica de los relatos hegemónicos del siglo XIX.

Con lo expuesto, es interesante indagar respecto del rol de los medios masivos de comunicación en la producción de sentidos y representaciones en tanto actores del sistema político. Sin embargo, con frecuencia la dimensión política y conflictiva de los medios queda desplazada u oculta por las connotaciones de "neutralidad", "mediación pacificadora" u "objetividad" en el tratamiento de la información (Borrat, 1989). Llevándolo a la cuestión indígena, sobre todo en los últimos años con la intensificación de los conflictos en la región de la Patagonia argentina y su visibilización en los medios de alcance nacional, se puso de manifiesto cómo unos y otros medios presentan una reconstrucción de la realidad social en función de los intereses políticos y económicos que sostienen y los presupuestos ideológicos que pretenden instalar en la agenda pública.

En Argentina esta situación de estigmatización y discriminación étnica no es una excepción. La tensión entre la necesidad de hacer visibles las demandas de los movimientos sociales se enfrenta a los intereses particulares de los medios de comunicación, que terminan por espectacularizar, sesgar o invisibilizar aspectos centrales de los movimientos sociales. La impronta colonial puede verse reflejada en el tratamiento mediático de los portales masivos de comunicación que perpetúan la cultura hegemónica dominante en Latinoamérica, invisibilizando y negando sistemáticamente a las culturas originarias. Por otra parte, la lógica del rating o el aumento de visitas, impacta en el tratamiento de la temática indígena como una "nota de color" o curiosidad, un evento aislado y espectacular o directamente como un hecho dramático o violento, cuando se trata de criminalizar las protestas sociales. Este relevamiento nos permite anticipar que, además de la búsqueda por un tratamiento igualitario en los medios de comunicación, es necesario contemplar otros canales alternativos de comunicación: mediáticos, interpersonales y de conquista del espacio público. En este sentido, cabe mencionar la importancia de las legislaciones en materia de comunicación y del rol del Estado garantizando un derecho esencial tal como la libertad de expresión.

A partir de los resultados presentados en este artículo nos proponemos continuar la investigación con nuevas hipótesis de trabajo y la incorporación de otras teorías y metodologías, como por ejemplo el Paradigma integral del Framing para analizar los encuadres noticiosos que los medios de comunicación presentan en el tratamiento de las temáticas de los pueblos indígenas. También proponemos una continuidad de este trabajo a partir de técnicas de análisis del discurso, que habilite un abordaje cualitativo de lo escrito y nos permita comparar con otras investigaciones en medios de comunicación en Latinoamérica, sistematizadas en este artículo.

\section{Agradecimientos}

Esta investigación fue financiada con fondos provenientes de los proyectos: "Investigación, Gestión y Significación Social del Patrimonio Cultural en el Centro de Buenos Aires y Centro-Este de San Luis" (PICT 0551/16 - ANPCyT) y "Estudio de las significaciones sociales del patrimonio cultural del partido de Olavarría, provincia de Buenos Aires. Propuesta metodológica para su visibilización y salvaguarda" (PIP 106/15- CONICET), dirigidos por la Dra. María Luz Endere; Proyecto de Incentivos a Docentes Investigadores del Ministerio de Educación de la Nación titulado: "Comunicación y problemas sociales, sus definiciones en el discurso periodístico" del Núcleo de investigación y Centro Asociado de la CIC-PBA Estudios de Comunicación y Cultura en Olavarría (ECCO) dirigido por la Dra. Mónica Cohendoz. También agradecemos a CONICET por financiar nuestras investigaciones doctorales. 


\section{Bibliografía}

Alonso, A. M. (1994). The politics of space, time and substance: state formation, nationalism, and ethnicity. Annual review of anthropology, 23(1), 379-405.

Andrada, D. (2016). Hacia un periodismo indígena. Buenos Aires: Ediciones Universidad de El Salvador.

Aparicio Wilhelmi, M. (2006). El derecho de los pueblos indígenas a la Libre Determinación. En M. Berraondo (Ed.), Pueblos indigenas y derechos humanos (pp. 399-421). Publicaciones de la Universidad de Deusto.

Aruguete, N. (2015). El poder de la agenda: política, medios y público. Buenos Aires: Biblos.

Balazote, A. y Radovich, J. C. (1999). Estudios antropológicos sobre la cuestión indígena en la Argentina. Minerva.

Bandeira de Melo, P. (2005). Agenda e Discurso Midiático: quando a minoria é notícia. O caso indígena na Imprensa em Pernambuco. In Ciências da Comunicação em Congresso na Covilhã (CCCC): actas do III SOPCOM, VI LUSOCOM, II IBÉRICO (pp. 177-182). Labcom-Laboratório de Comunicação e Conteúdos Online.

Becerra, M. (2018). Transformaciones, cambios en el ecosistema y nuevos actores en la era de la digitalización de los flujos de información y comunicación. En Álvarez Nobell, A., Becerra, M., Codeseira, S., Dessein, D., Geoghegan, B., Mociulsky, M., Olivera, S., Palloti, C., Roitberg, G. y Rottman, D. La vida digital de los medios y la comunicación: ensayos sobre las audiencias, el contenido y los negocios en internet (pp. 18-42). Ediciones Granica S.A.

Bellucci, M. y Rapisardi, F. (1999). Alrededor de la identidad. Las luchas políticas del presente. Nueva Sociedad, 162, 40-53.

Bezerra, A. A. S. (2018). Violações dos direitos dos povos indígenas: os meios de comunicação no caso Tupinambá. Revista Interdisciplinar de Direitos Humanos, 6 (1), 129-145. https://www3. faac.unesp.br/ridh/index.php/ridh/article/view/573/242

Bidaseca, K. (2011). Signos de la identidad indígena. Emergencias identitarias en límite del tiempo histórico. Editorial SB.

Borrat, H. (1989). El periódico, actor del sistema político. Anàlisi: Quaderns de comunicació $i$ cultura, (12), 67-80.

Braga, C. F., y Campos, P. H. F. (2012). Invisíveis e subalternos: as representações sociais do indígena. Psicologia y Sociedade, 24 (3), 499-506. https://doi.org/10.1590/S010271822012000300003.

Brown Givens, S. M., y Monahan, J. L. (2005). Priming mammies, jezebels, and other controlling images: An examination of the influence of mediated stereotypes on perceptions of an African American woman. Media Psychology, 7(1), 87-106.

CHIRAPAQ (2013). Racismo, medios de comunicación y pueblos indígenas. SINCO Editores SAC.

Colle, R. (2011). El análisis de contenido de las comunicaciones (9th ed.). La Laguna: Sociedad Latina de Comunicación Social. 
Comscore MMX, Multiplataforma (2020) Usuarios de medios digitales Total Unique Visitors/ Viewers,2017-2020 Argentina. Recuperado de https://medium.com/@jpdesantis/mapa-de-mediosdigitales-2020-5fb3bd40c015

Crespo, C. (2011). Patrimonio arqueológico, memoria y territorio: Procesos de autoctonización entre los mapuches de Lago Puelo, Chubut (Patagonia, Argentina). Frontera norte, 23(45), 231255.

Curtoni, R. (2014). Multivocalidad, Geopolítica y Patrimonio: Prácticas situadas entre los Rankulches del centro de Argentina. En C. Giannotti García, D. Barreiro Martínez y B. Vienni Baptista (coords.), Patrimonio y Multivocalidad: Teoría, Práctica y Experiencias en torno a la construcción de conocimiento en patrimonio (pp. 115-124).Universidad de la República.

De la Roca, E. A. S. (2015). El concepto de subsunción en los períodos históricos tempranos en los Andes. Investigaciones sociales, 19(34), 37-51.

Díaz, F. y Ferreiros, E. (2016). Es necesario un periodismo indígena que visibilice la lucha, que se sume a la agenda diaria y que hable del territorio. En Andrada, D. (2016). Hacia un periodismo indigena (pp. 179-190). Buenos Aires: Ediciones Universidad de El Salvador.

Dixon, T. (2000). A social cognitive approach to studying racial stereotyping in the mass media. African American Research Perspectives, 6(1), 60-68.

Doyle, M., Belotti, F. y Siares, E. (2016). Los medios de pueblos originarios en América Latina: historia, aproximaciones y desafíos. En Andrada, D. (2016). Hacia un periodismo indígena (pp. 203-218). Buenos Aires: Ediciones Universidad de El Salvador.

Durán Santoyo, O. (2000). Presencia, Representación y Temas Indígenas en la Prensa Mexicana: Análisis de Contenido de La Jornada, El Norte, Proceso y época desde la Teoría de la Agenda Setting y la Sociología de la Producción de mensajes durante el año 2000. (Tesis inédita de maestría). Instituto Tecnológico y de Estudios Superiores de Monterrey, Monterrey.

Escolar, D., Delrio, W., y Malvestitti, M. (2010). Criminalización y distorsión de las demandas indígenas en Argentina. La construcción mediática del pueblo Mapuche como no-originario. Journal de la société des américanistes, 96 (96-1), 293-295.

Fabián, J. (2016). La Tribuna y El Nacional: la cobertura de la prensa escrita sobre la "Conquista del Desierto”. En Andrada, D. (2016). Hacia un periodismo indígena (pp. 103-118). Buenos Aires: Ediciones Universidad de El Salvador.

Forte, M.A (2016). De la Zanja de Alsina a los imaginarios nacionales: el tajo, el Remington y los ecos de La Marsellesa. En Andrada, D. (2016). Hacia un periodismo indígena (pp. 135-148). Buenos Aires: Ediciones Universidad de El Salvador.

Gertz, H. L. D. Amazônia brasileira e indígenas na revista Der Spiegel: representação e estereótipo no jornalismo internacional. https://casperlibero.edu.br/wp-content/uploads/2017/02/ Helena-L\%C3\%ADvia-Dedecek-Gertz-\%E2\%80\%93-UFRGS.pdf

Ghanem, S. I. (1997). El segundo nivel de composición de la agenda: la opinión pública y la cobertura del crimen. Comunicación y sociedad. Vol X, No 1, p. 151-167.

Gitlin, T. (1986). Convertir a los movimientos de protesta en temas periodísticos. En D. Graiber (ed.). El poder de los medios en la política, Buenos Aires: GEL, pp. 289-302.

Hammersley, M. y Atkinson, P. (1994). Etnografia. Métodos de investigación. Paidós. 
Hudson, E., del Valle, C., y Browne, R. (2020). Análisis de la relevancia informativa en la cobertura del tema mapuche en la prensa nacional y regional de Chile. University of Groningen Press.

Koziner, N. (2018). Periodistas y fuentes en la prensa argentina. Revisión teórica a partir de un caso empírico. Revista mexicana de opinión pública, (24), 147-167.

Lazzari, A. (2007). Identidad y fantasma: situando las nuevas prácticas de libertad del movimiento indígena en La Pampa. Quinto sol, 11 , 91-122.

Lazzari, A. C., Rodríguez, M. E., y Papazian, A. E. R. (2015). Juegos de visibilización: Antropología sociocultural de los pueblos indígenas en Pampa y Patagonia. Papeles de trabajo, 9 (16), 56-109.

Lenton, D. (2014). Apuntes en torno a los desafíos que derivan de la aplicación del concepto de genocidio en la historia de las relaciones entre el estado argentino y los pueblos originarios. En J. L. Lanata (comp.). Prácticas Genocidas y Violencia Estatal en Perspectiva Transdisciplinar (pp. 32-51). IIDyPCa-CONICET.

Lenton, D; Delrio, W.; Pérez, P.; Papazian, A.; Nagy, M. y Musante, M. (2015). Huellas de un genocidio silenciado: los indígenas en Argentina. Conceptos, 90 (493), 119-142.

Lins Ribeiro, G. (1989). Descotidianizar. Extrañamiento y conciencia práctica. Un ensayo sobre la perspectiva Antropológica. Cuadernos de Antropología Social, 2 (1), 65-68.

Lois, I. (2016). La comunicación popular y comunitaria desde una perspectiva intercultural. En Andrada, D. (2016). Hacia un periodismo indígena (pp. 119-134). Buenos Aires: Ediciones Universidad de El Salvador.

Marcet, J. M. C., \& María, J. (1997). Periodismo de investigación: teoría y práctica. España: Síntesis.

Mariano, M. (2011). Patrimonio intangible e identidad: representaciones bolivianas en Olavarría, provincia de Buenos Aires, Argentina. Intersecciones en antropología, 12(1), 83-94.

McCombs, M. (1992) Explorers and surveyors: Expanding strategies for agenda-setting research, Journalism Quarterly, 69(4), 813-824. https://doi.org/10.1177/107769909206900402

McCombs, M., Llamas, J. P., López Escobar, E., \& Rey Lennon, F. (1997). Candidate Images in Spanish Elections: Second-level Agenda-Setting Effect. Journalism and Mass Communication Quarterly, 74(4), 703-717.

McCombs, M., \& Evatt, D. (1995). Los temas y los aspectos: explorando una nueva dimensión de la agenda setting. Comunicación y sociedad, 8(1), 7-32

McCombs, M. (2006). Cómo funciona el establecimiento de agenda. En McCombs, M. (2006). Estableciendo la agenda: el impacto de los medios en la opinión pública y en el conocimiento. Barcelona: Grupo Planeta.

Melucci, A. (1996). Challenging codes: Collective action in the information age. Cambridge University Press.

Millán, M. y Margarucci, I. (2016). Los medios de comunicación se han encargado de demonizar la imagen de los pueblos originarios. En Andrada, D. (2016). Hacia un periodismo indígena (pp. 163-178). Buenos Aires: Ediciones Universidad de El Salvador. 
Mitchelstein, E. \& Boczkoski, P. (2018). Argentina. Digital News Report 2018. Reuters Institute for the Study of Journalism, pp. 114-115. Recuperado de: http://media.digitalnewsreport.org/wpcontent/uploads/2018/06/digital-news-report-2018.pdf

Nagy, M. A. (2018). Un relato perdurable: la realización simbólica en el genocidio de los pueblos originarios en Argentina. Revista de Estudios sobre Genocidio, 13 (9), 63-80.

Núñez, A. (2013). La frontera no deja ver la montaña: invisibilización de la cordillera de Los Andes en la Norpatagonia chileno-argentina. Revista de Geografia Norte Grande, (55), 89-108.

Ñanku, R. y Wahnish, G. (2016). La comunicación es una de las armas y herramientas más fuertes para presionar a los gobiernos para reformar sus políticas. En Andrada, D. (2016). Hacia un periodismo indígena (pp. 149-162). Buenos Aires: Ediciones Universidad de El Salvador.

Ottaviano, C. y Lamas, E. (2016). Comunicar con identidad, un camino hacia la soberanía comunicacional. En Andrada, D. (2016). Hacia un periodismo indígena (pp. 87-102). Buenos Aires: Ediciones Universidad de El Salvador.

Palomo, C. y González, M. (2016). Los pueblos indígenas tenemos que recuperar nuestra propia palabra, hablarla nosotros y para nosotros. En Andrada, D. (2016). Hacia un periodismo indígena (pp. 191-202). Buenos Aires: Ediciones Universidad de El Salvador.

Pérez García, A. Y. (2018). Un análisis de la cobertura periodística de Marichuy en los diarios La Jornada y Excélsior. Revista Flectere, (1).

Piñuel Raigada, J. L. (2002). Epistemología, metodología y técnicas del análisis de contenido. Estudios de Sociolingüística, 3(1), pp. 1-42.

Peterson, A., \& Thörn, H. (1999). Movimientos sociales y modernidad de los medios de comunicación: industrias de los medios de comunicación, ¿amigos o enemigos?. Comunicación y Sociedad, (35), 11-44.

Quijano, A. (2007). Don Quijote y los molinos de viento en América Latina. En Kozlarek O. (coord.) De la teoría crítica a una crítica plural de la modernidad (pp. 123-146). Biblos.

Reguillo, R. (2000). Movimientos sociales y comunicación: el espejo cóncavo y la irrupción indígena. América Latina Hoy, 25, 67-76.

Rovira-Sancho, G. (2013). Activismo mediático y criminalización de la protesta: medios y movimientos sociales en México. Convergencia, 20 (61), 35-60.

Sáez Gallardo, J. (2018). El racismo discursivo en la prensa escrita: una mirada teórica desde el Análisis Crítico del Discurso y la Sociología de los medios. https:/ojs.ehu.eus/index.php/Zer/ article/view/19995

Saldierna Salas, A. R. (2011). Impacto mediático sobre el apoyo a las medidas políticas dirigidas hacia indígenas: evaluación del posicionamiento de la población mexicana. (Tesis inédita de maestría). Universidad Autónoma de Nuevo León, Monterrey.

Siqueira Toguchi, I. (2016). A gramática do preconceito: estudo cognitivo-funcional do discurso jornalístico sobre o indígena brasileiro. (Tesis inédita de doctorado). Universidad de Brasilia, Brasilia.

Sirpa Tambo, J. (2016). Pukara: una experiencia de comunicación de los indios para los indios. En Andrada, D. (2016). Hacia un periodismo indígena (pp. 219-234). Buenos Aires: Ediciones Universidad de El Salvador. 
Smith, J., McCarthy, J. D., McPhail, C., \& Augustyn, B. (2001). From protest to agenda building: Description bias in media coverage of protest events in Washington, DC. Social Forces, 79(4), 1397-1423. https://www.jstor.org/stable/2675477

Stavenhagen, R. (2007). Los Pueblos Indigenas y sus derechos. UNESCO.

Trouillot, M. R. (1995). Silencing the past. Power and the Production of History. Beacon Press.

Valverde, S. (2013). De la invisibilización a la construcción como sujetos sociales: el pueblo indígena Mapuche y sus movimientos en Patagonia, Argentina. Anuário Antropológico, (1), 139166.

Zunino, E., y Aruguete, N. (2010). La cobertura mediática del conflicto campo-gobierno. Un estudio de caso. Global Media Journal, 7 (14), 1-23.

Zunino, E. (2016). La relevancia de las noticias en la prensa gráfica: Una reflexión teóricometodológica a partir del análisis del conflicto entre las corporaciones agrarias y el gobierno argentino. Comunicación y sociedad, (25), 127-156.

Zunino, E. (2018). Agenda Setting: Cincuenta años de investigación en Comunicación. Intersecciones en Comunicación; p. 187 - 210. Olavarría: Facultad de Ciencias SocialesUNICEN. 